\title{
OS OBJETOS DE ESTUDO DA PRIMEIRA DÉCADA DE PESQUISAS DA LINHA DE MÍDIAS E IDENTIDADES CONTEMPORÂNEAS (POSCOM/UFSM)
}

\author{
The objects of study in the first decade of research in \\ Media and Contemporary Identities line (POSCOM/UFSM)
}

Los objetos de estudio de la primera década de investigación en la línea de Medios e Identidades Contemporáneas (POSCOM/UFSM)

Guilherme Oliveira Curi Pós-doutorando e professor colaborador do Programa de Pós-Graduação em Comunicação da Universidade Federal de Santa Maria (POSCOM/UFSM) curi.guilherme@gmail.com

Bruno Kegler

Docente da Universidade de Santa Cruz do Sul (UNISC) e pós-doutorando do Programa de Pós-Graduação em Comunicação da Universidade Federal de Santa Maria (POSCOM/UFSM) brunokegler@gmail.com

Camila Hartmann Doutoranda do Programa de Pós-Graduação em Comunicação da Universidade Federal de Santa Maria (POSCOM/UFSM) camilahartmann6@gmail.com

Helyna Dewes Doutoranda do Programa de Pós-Graduação em Comunicação da Universidade Federal de Santa Maria (POSCOM/UFSM) helyna.dewes@gmail.com

\section{Resumo}

No presente artigo analisamos os objetos empíricos selecionados para as investigações desenvolvidas na linha de pesquisa Mídias e Identidades Contemporâneas do Programa de PósGraduação em Comunicação da Universidade Federal de Santa Maria (UFSM). Consideramos como fonte de dados as dissertações e teses referentes à primeira década de produção efetiva do programa (2008-2017). O objetivo principal é identificar os objetos empíricos que foram submetidos ao exame científico e, como objetivo secundário, buscamos tecer alguns comentários e distinções acerca dos modos como os objetos do mundo - aquilo que se analisa - são estudados. Os resultados encontrados apontam para a predominância de pesquisas sobre a televisão $(45,45 \%)$, seguida pelo jornal impresso $(12,12 \%)$ e pela internet $(10,60 \%)$.

Palavras-chave: Objeto de estudo. Mídias e Identidades Contemporâneas. Pós-Graduação em Comunicação. 


\begin{abstract}
In this article we analyze the empirical objects selected for the investigations developed at the Media and Contemporary Identities Studies as part of the Postgraduate Program in Communication at Federal University of Santa Maria (UFSM). We have considered as a data source the dissertations and theses related to the first decade of effective production of the program (2008-2017). The main objective is to identify the empirical objects that were submitted to scientific examination and, as a secondary objective, we seek to make some comments and distinctions about the ways in which the objects of the world - what is analyzed - are studied. The final results pointed to the predominance of television surveys $(45,45 \%)$, followed by printed newspaper $(12,12 \%)$ and internet $(10,60 \%)$.
\end{abstract}

Key words: Object of study. Media and Contemporary Identities. Post-Graduation in Communication.

\title{
Resumen
}

En este artículo analizamos los objetos empíricos seleccionados para las investigaciones desarrolladas en la línea de investigación sobre Medios e Identidades Contemporáneas del Programa de Posgrado en Comunicación de la Universidad Federal de Santa María (UFSM). Lo consideramos como fuente de datos para análisis las disertaciones y tesis relacionadas con la primera década de producción efectiva del programa (2008-2017). El objetivo principal es identificar los objetos empíricos que fueron sometidos a examen científico y, como objetivo secundario, buscamos hacer algunos comentarios y distinciones sobre las formas en que se estudian los objetos del mundo - lo que se analiza. Los resultados finales apuntan al predominio de las encuestas televisivas $(45,45 \%)$, seguidas del periódico impreso $(12,12 \%)$ e internet $(10,60 \%)$.

Palabras clave: Objeto de estudio. Medios e Identidades Contemporáneas. Posgrado en Comunicación.

\section{INTRODUÇÃO}

Pesquisar é estar atento ao gosto do tempo presente e às mudanças do tempo futuro em diálogo constante com o passado. Esse é um dos principais atributos das chamadas ciências humanas contemporâneas. O surgimento e a criação dos programas de pós-graduação em comunicação no Brasil, assim como nos principais países latino-americanos, a partir dos anos 1970, não fugiu desta caraterística basilar. Desde então, evidenciou-se a necessidade de aprimoramento da pesquisa e do ensino de acordo com as necessidades da época. A demanda refletia diretamente a evolução dos meios de comunicação e do mercado de trabalho, tornando imprescindível a constituição de espaços de formação docente e de pesquisadores voltados ao aprimoramento profissional e à compreensão crítica das dinâmicas sociais em sua relação com o campo comunicacional.

A análise de transformações na sociedade oriundas dos produtos midiáticos possui uma vocação interdisciplinar, uma vez que mobiliza distintos campos do conhecimento, para além 
do viés comunicacional. O estudo dos objetos empíricos oportuniza o aperfeiçoamento dos processos envolvidos na constituição dos produtos veiculados pelos meios de comunicação (MARQUES DE MELO, 2003), foco principal do texto aqui proposto.

Ainda, a pesquisa em comunicação na América Latina surge também em um contexto político de regimes autoritários, de golpes civis-militares e democracias frágeis. O objetivo dos primeiros estudos era de fato mostrar como os meios de comunicação se articulavam na construção de hegemonias políticas vigentes. A crítica aos meios de comunicação era uma forma de denúncia ao sistema político, fato que talvez explique, por exemplo, o sucesso, no Brasil, da Teoria Crítica da Escola de Frankfurt, ou das teorias do Estruturalismo francês que apontavam a participação da grande mídia corporativa hegemônica nos regimes políticos da época.

Além disso, há um segundo elemento a ser considerado nesse cenário. Ao longo do século XX, a chamada "cultura de massa" produzida nos Estados Unidos, sobretudo os filmes de Hollywood, espalharam-se por todo planeta. Na América Latina, sua presença era às vezes vista com desconfiança em relação à divulgação da cultura norte-americana e sua articulação com as culturas locais. Ao mesmo tempo, formas culturais específicas se desenvolveram nas décadas seguintes a partir de matrizes culturais/contra culturais latino-americanas em determinados países, como Uruguai, Chile, Argentina e Colômbia.

Dentro deste contexto histórico, acadêmico e interdisciplinar latino-americano, o Programa de Pós-Graduação em Comunicação (POSCOM) da Universidade Federal de Santa Maria (UFSM) inicia suas atividades em 2005 e define sua área de concentração como Comunicação Midiática, tendo em vista a ação das mídias na sociedade, em distintas esferas, e sua contribuição na configuração das identidades contemporâneas.

Após a análise da primeira década de produção científica do POSCOM, especificamente, das 66 teses e dissertações da linha de pesquisa Mídias e Identidades Contemporâneas, que realizamos em Kegler et al. (2020), lançamos nosso olhar mais especificamente sobre os objetos empíricos selecionados para essas investigações.

O presente artigo origina-se da necessidade de uma observação interna, fruto do recorte realizado na investigação citada, diferenciando-se da outra linha de pesquisa do POSCOM da UFSM, Mídias e Estratégias Comunicacionais, uma vez que se compreendem como específicas as distintas teorias e metodologias, características de cada uma dessas linhas. Nossos objetivos neste estudo são descrever os objetos empíricos na visão da linha de pesquisa e, juntamente, analisar em alguns casos a perspectiva de diferentes abordagens para os mesmos objetos. 
A relevância em observarmos a produção científica da linha de pesquisa Mídias e Identidades Contemporâneas reside no fato de encontrarmos somente outros dois programas de pós-graduação em comunicação que também possuem interesse direto na temática: Mídia, Identidade e Regionalidade, da Universidade Federal do Mato Grosso do Sul, e Comunicação, Poder e Identidades, da Universidade Federal do Tocantins. Outros programas citam as questões identitárias na descrição de suas linhas, mas não carregam o termo "identidade" em suas denominações, como nos programas de pós-graduação em comunicação da Pontifícia Universidade Católica do Rio de Janeiro, da Escola Superior de Propaganda e Marketing, das Universidades Federais Fluminense, de Goiás, do Pará, Piauí e do Recôncavo Baiano.

O artigo estrutura-se a partir desta introdução e de outras três partes. A seguir, debatemos sobre a configuração dos objetos de estudo da linha de pesquisa Mídias e Identidades Contemporâneas e sua contextualização no campo comunicacional. Após, apresentamos os dados do levantamento realizado e, por fim, trazemos algumas considerações finais sobre o estudo desenvolvido.

\section{DOS OBJETOS DE ESTUDO DA LINHA DE MÍDIAS E IDENTIDADES CONTEMPORÂNEAS}

A compreensão dos objetos de estudo deslinda pistas acerca dos modos como os problemas do mundo são analisados pelas pesquisas desenvolvidas na linha de Mídias e Identidades Contemporâneas. Diferentemente do que realizamos em Kegler et al. (2020), em que traçamos um mapeamento descritivo que possibilitou uma visão panorâmica acerca daqueles estudos - por conseguinte, da constituição da linha de pesquisa que se singulariza nas particularidades e convergências do conjunto de estudos que abarca - a partir de múltiplos critérios, neste artigo delimitamos a nossa visada aos objetos estudados nas teses e dissertações defendidas na primeira década de atividades do POSCOM.

Neste sentido, guiados por França (2016), poderíamos seguir dois caminhos de investigação a partir de duas dimensões diferentes do objeto, o objeto empírico - aquilo que se estuda - e o objeto de conhecimento - como estudar o objeto empírico enquanto de comunicação. Não se trata de hierarquizar ou de opor as duas dimensões, a empírica versus a teórica, por exemplo, mas de sublinhar justamente o contrário, que é como a reflexão teórica se constrói na leitura e na busca de compreensão das coisas do mundo, a realidade. Em consonância, Lopes (2003) reitera a relevância da instância epistemológica e teórica em todas 
as fases da pesquisa científica, desde a construção do objeto de estudo até a interpretação dos dados coletados.

A interdependência entre as duas dimensões fica evidente pelo reconhecimento de que se, por um lado, a observação da realidade tenciona à reflexão, por outro, qualquer reflexão é sempre ancorada em saberes ou pressupostos, ou seja, sob uma determinada perspectiva. Desta conjunção, empiria e teoria, resulta o objeto empírico que "categoriza e trata de uma determinada maneira - e não de outra - o mundo do empírico" (FRANÇA, 2016, p. 157). Como diz Braga (2011), o objeto empírico é a porta de acesso à compreensão do objeto de pesquisa, este - na mesma perspectiva da noção de objeto de conhecimento (FRANÇA, 2016) constituído a partir de uma perspectiva teórica de referência.

Os objetos empíricos da comunicação são as ações sociais comunicacionais (BRAGA, 2011) e estas podem ser submetidas a diferentes olhares, inclusive de outras ciências. É ilustrativo reconhecer, nesta direção, que o processo de plataformização do trabalho pode ser objeto de estudo para o campo da comunicação, da sociologia e do direito do trabalho, por exemplo. Por isso, França (2016) defende que objetos e ações são objetos comunicacionais somente a partir do momento em que o pesquisador os vê como tal, numa dimensão comunicativa.

Assim, qualquer interação humana, observada enquanto comunicação, dá origem a um objeto comunicacional, seja com ou sem a mediação de suportes midiáticos. Tendo isto em vista, pode-se dizer não são estes que definem a singularidade da Comunicação enquanto campo científico, nem tampouco eles lhes são exclusivos, ainda que seja reconhecido que a sua constituição decorre do surgimento dos meios de comunicação de massa e as suas implicações organizativas para as sociedades no século XX.

Com esses pressupostos, guiamos o nosso olhar para a coleta e a análise dos dados junto às teses e dissertações da linha de Mídias e Identidades Contemporâneas, com o objetivo principal de identificar os objetos empíricos que foram submetidos ao exame científico em sua primeira década. Como objetivo secundário, buscamos tecer alguns comentários e distinções acerca dos modos como os objetos do mundo - aquilo que se analisa - são estudados. Esperase com isso ilustrar, ainda que brevemente, essas duas dimensões, a do objeto empírico e a do objeto de conhecimento; ou seja, como são tornados objetos de Comunicação. Ademais, entendemos que esta orientação analítica nos permite sublinhar que apesar de a área de concentração do POSCOM ser Comunicação Midiática, e de haver nas pesquisas a prevalência 
de objetos empíricos midiáticos, não se trata apenas disto, há análises que se dedicam a ações sociais marginais à cena midiática ou às ambiências digitais contemporâneas.

O grande número de objetos empíricos midiáticos selecionados para análise nas investigações em comunicação, para Braga (2011), explica-se pela possibilidade de objetivação e problematização dos processos comunicacionais, uma vez que foi somente a partir dos meios de comunicação que a sociedade se percebeu em interação com ela mesma. De acordo com Marques de Melo (2003), a configuração desses objetos ocorre também pela legitimação empírica realizada pelos manuais produzidos nos espaços corporativos, pela assimilação universitária que emerge das demandas empresariais e sociais e pelo reconhecimento acadêmico refletido nos programas de ensino e no desenvolvimento das pesquisas teóricas. A forte presença de objetos empíricos midiáticos nas pesquisas em comunicação possui também um fator histórico, pois

[...] o primeiro objeto comunicacional a suscitar estudos (pesquisas) e a demandar sistematização (ensino) foi a imprensa (século XIX), ensejando o nascimento de duas disciplinas - bibliologia e hemerografia. Depois apareceu o jornalismo, inicialmente em sua vertente impressa, depois enveredando pela difusão através de outros meios massivos: cinejornalismo, radiojornalismo (primeira metade do século XX) e ciberjornalismo (segunda metade do século XX) (MARQUES DE MELO, 2003, p. 39).

Desse modo, trata-se de reconhecer que, por si só, as mídias não se constituem como objeto comunicacional, o que só se materializa sob a ótica do pesquisador. Na seção seguinte, descrevemos o processo investigativo que desempenhamos, bem como os resultados e as análises destes.

\section{ANTECEDENTES DA PESQUISA E PERCURSO DA COLETA DE DADOS E DA ANÁLISE}

A presente pesquisa se delimita à identificação e à análise dos objetos de estudo da linha de pesquisa Mídias e Identidades Contemporâneas (POSCOM/UFSM) no período de 2008 a 2017, a primeira década desde a sua criação. Trata-se da segunda parte da apresentação dos resultados da pesquisa iniciada em agosto de 2020, cujo primeiro conjunto de respostas foi apresentado em Kegler et al. (2020). Nosso esforço principal, nessas duas fases, consiste em uma pesquisa exploratória (GIL, 2010) para delinear o estado da arte da linha de pesquisa supramencionada e, assim, identificar, salientar e discutir os principais caracterizadores teóricos e metodológicos desses estudos. 
Das etapas realizadas, a constituição do corpus empírico foi feita via Manancial, o repositório digital da UFSM, entre os dias 10 e 12 de agosto de 2020, recorte temporal que permitiu reunir 56 dissertações e 10 teses, todas elas defendidas na primeira década de pesquisas, conforme ilustrado na Tabela 1.

Tabela 1 - Dissertações e teses por ano de publicação

\begin{tabular}{|c|c|c|c|}
\hline Ano da publicação & Dissertação (D) & Tese (T) & Total (D+T) \\
\hline 2008 & 5 & 0 & 5 \\
\hline 2009 & 3 & 0 & 4 \\
\hline 2010 & 4 & 0 & 9 \\
\hline 2011 & 9 & 0 & 7 \\
\hline 2012 & 7 & 0 & 3 \\
\hline 2013 & 3 & 0 & 4 \\
\hline 2014 & 4 & 0 & 6 \\
\hline 2015 & 6 & 4 & 13 \\
\hline 2016 & 9 & 6 & $\mathbf{6 6}$ \\
\hline 2017 & 6 & $\mathbf{1 0}$ & \\
\hline Total & $\mathbf{5 6}$ & & 0 \\
\hline
\end{tabular}

Fonte: Kegler et al. (2020).

Definido o corpus empírico, foram estabelecidos os itens para a coleta de dados do presente artigo, que ocorreu entre os dias 3 e 14 de novembro. As análises, por sua vez, foram feitas entre os dias 15 e 30 de novembro de 2020. A sistematização dos resultados da coleta está posta em uma tabela elaborada no software Word onde inserimos os dados extraídos das teses e dissertações analisadas.

A tabela contém cinco colunas. A primeira, intitulada "objeto midiático", reúne a tipificação do meio de comunicação ou o tipo de interação estabelecida para a análise. Em suma, trata-se dos objetos empíricos, dos quais se desdobram os objetos de conhecimento sob perspectivas teóricas e metodológicas diversas. Nesta coluna, dispostas linha-a-linha, estão as seguintes classificações, conforme as denominações encontradas nas 66 pesquisas: jornal impresso, televisão, cinema, internet, revista, música, meios de divulgação científica e, por fim, outro/não tem objeto midiático. 
Na segunda coluna, denominada "tipo de objeto midiático", foi especificado qual parte ou o quê do objeto midiático e/ou, no caso da última linha, não midiático foi analisada. Para exemplificar, em "música", estabelecemos as seguintes diferenciações: "rap" e "tchê music e música campeira", conforme encontrado nas dissertações ou teses.

Na terceira coluna, intitulada "veículo/título", e em busca de avançar na especificação dos objetos comunicacionais, inserimos o nome das empresas de comunicação (Zero Hora, Rede Globo de Televisão, e assim por diante), dos filmes ou documentários, dos programas ou noticiários televisivos, conforme a correspondência com a coluna "objeto midiático". Cabe observar que, assim como para "tipo de objeto midiático", há estudos que reúnem mais de um veículo ou título, o que mantivemos na elaboração da tabela.

$\mathrm{Na}$ quarta coluna, "dissertações/teses", sinalizamos o total de dissertações e o total de teses que trabalharam com o objeto midiático em referência a cada linha. Por fim, na quinta coluna, "total de ocorrências (\%)", inserimos o número total de trabalhos (a soma, portanto, das teses e dissertações alocadas na quarta coluna) que versaram sobre cada um dos objetos midiáticos designados e o percentual relativo ao total de pesquisas analisadas (66). Ilustrando todas essas considerações, apresentamos a Tabela 2.

Tabela 2 - Coleta de dados alusiva aos objetos empíricos

\begin{tabular}{|c|c|c|c|c|}
\hline $\begin{array}{l}\text { Objeto } \\
\text { midiático }\end{array}$ & $\begin{array}{l}\text { Tipo de objeto } \\
\text { midiático }\end{array}$ & Veículo/título & $\begin{array}{l}\text { Dissertações } \\
\text { /teses }\end{array}$ & $\begin{array}{l}\text { Total de } \\
\text { ocorrências (\%) }\end{array}$ \\
\hline $\begin{array}{l}\text { Jornal } \\
\text { impresso }\end{array}$ & $\begin{array}{l}\text { Notícias/opinião/ } \\
\text { reportagem (4); } \\
\text { anúncios } \\
\text { publicitários (2); } \\
\text { fontes } \\
\text { especializadas } \\
\text { consultadas pelo } \\
\text { veículo (1); } \\
\text { coluna social (1) }\end{array}$ & $\begin{array}{l}\text { Zero Hora (3); Diário de Santa Maria } \\
\text { (2), Extra (1); A Razão (2); Diário } \\
\text { Gaúcho (1); A Voz do Treze (1) }\end{array}$ & $7 / 1$ & $8(12,12 \%)$ \\
\hline Televisão & $\begin{array}{l}\text { Programete (1); } \\
\text { programa (4); } \\
\text { telenovela (4); } \\
\text { série especial (1); } \\
\text { série ficcional (1); } \\
\text { filme não } \\
\text { ficcional (1); } \\
\text { sitcom (2); } \\
\text { comercial (2); } \\
\text { campanha } \\
\text { publicitária (1); } \\
\text { anúncio } \\
\text { publicitário (3); } \\
\text { telejornal (5); }\end{array}$ & $\begin{array}{l}\text { Rede Globo de Televisão - } \\
\text { telenovelas: Caminho das Índias (1), } \\
\text { Malhação (1), Passione (2), Avenida } \\
\text { Brasil (1); programas: Novo (1), } \\
\text { Esquenta (2), Esporte Espetacular (1); } \\
\text { sitcom: A Grande Família (1), Os } \\
\text { Normais (1), Fantasias de uma dona } \\
\text { de casa (1); telejornal Jornal Nacional } \\
\text { (1); série especial com os jogadores } \\
\text { da Seleção Brasileira convocados } \\
\text { para a Copa do Mundo de } 2014 \text { (1); } \\
\text { entradas ao vivo durante a cobertura } \\
\text { da tragédia da boate Kiss (1 - estudo } \\
\text { inclui concomitantemente a RBS }\end{array}$ & $26 / 4$ & $30(45,45 \%)$ \\
\hline
\end{tabular}




\begin{tabular}{|c|c|c|c|c|}
\hline & $\begin{array}{l}\text { audiovisual (1); } \\
\text { campanha } \\
\text { autopromocional } \\
\text { (1); entrada ao } \\
\text { vivo (1); especial } \\
\text { (1); seriado de } \\
\text { caráter factual (1) }\end{array}$ & $\begin{array}{l}\text { TV); séries ficcionais Queridos } \\
\text { amigos e Magnífica } 70 \text { (1 - estudo } \\
\text { inclui concomitantemente a HBO) } \\
\text { RBS TV - programete Preserve o que } \\
\text { é nosso (1); programa Fora do Ar (1); } \\
\text { campanha autopromocional } \\
\text { comemorativa de } 50 \text { anos da RBS TV } \\
\text { (1); telejornal Jornal do Almoço (1); } \\
\text { especiais Bah! Um programa muito } \\
\text { gaúcho, Bah! Eu Sou do Sul e Bah! } \\
\text { Um fandango muito especial (1) } \\
\text { Rede Bandeirantes - Programa Ponto } \\
\text { de Luz (1) } \\
\text { Canais Dez Saeta, Montecarlo TV do } \\
\text { Canal Quatro e Doze - telejornais } \\
\text { Subrayado, Telenoche, Teledoce (1); } \\
\text { Televisión América Latina - seriado } \\
\text { factual Os latino-americanos (1) } \\
\text { RBS TV Chapecó - telejornal Jornal } \\
\text { do Almoço (1) } \\
\text { RICTV Record - telejornal Jornal do } \\
\text { Meio dia (1) } \\
\text { TV OVO - audiovisuais diversos (1); } \\
\text { filmes não ficcionais (1) } \\
\text { Não especificado (7) }\end{array}$ & & \\
\hline Cinema & $\begin{array}{l}\text { Documentário (4); } \\
\text { filme (curta- } \\
\text { metragem) (1) }\end{array}$ & $\begin{array}{l}\text { Walachai (1); Berlim Brasil (1); } \\
\text { Doble Chapa (1); Linha Imaginária } \\
\text { (1); documentários queer (1); filmes } \\
\text { brasileiros em acervos relacionados } \\
\text { ao circuito exibidor em Nova Iorque } \\
\text { (1) }\end{array}$ & $3 / 2$ & $5(7,57 \%)$ \\
\hline Internet & $\begin{array}{l}\text { Orkut (1); } \\
\text { Facebook (4); } \\
\text { jornal online (1); } \\
\text { YouTube (1); }\end{array}$ & $\begin{array}{l}\text { Orkut - comunidades virtuais (1) } \\
\text { Facebook - eventos (1); página e } \\
\text { grupo de discussão (1); comunidade } \\
\text { (1); perfis, postagens e comentários } \\
\text { em grupos (1) } \\
\text { Jornal online Última Hora - matérias } \\
\text { e comentários (1) } \\
\text { YouTube - vídeo digital (1) }\end{array}$ & $6 / 1$ & $7(10,60 \%)$ \\
\hline Revista & $\begin{array}{l}\text { Notícias e } \\
\text { reportagens (3); } \\
\text { reportagem de } \\
\text { capa (1); anúncios } \\
\text { publicitários (1); } \\
\text { editoriais (1) }\end{array}$ & $\begin{array}{l}\text { Galileu (1); Simples (1); Vogue } \\
\text { Brasil (1); Veja (1); Carta Capital (1); } \\
\text { Revista do Brasil (1); } \\
\text { Superinteressante (1) }\end{array}$ & $5 / 1$ & $6(9,09 \%)$ \\
\hline
\end{tabular}


PROGRAMA DE PÓS-GRADUAÇÃO EM COMUNICAÇÃO DA UNIVERSIDADE FEDERAL DE SANTA MARIA

\begin{tabular}{|c|c|c|c|c|}
\hline Música & $\begin{array}{l}\text { Rap (1); tchê } \\
\text { music e música } \\
\text { campeira (1) }\end{array}$ & Raps nacionais (1); não especifica (1) & $2 /-$ & $2(3,03 \%)$ \\
\hline $\begin{array}{l}\text { Meios de } \\
\text { divulgação } \\
\text { científica }\end{array}$ & $\begin{array}{l}\text { Papers de anais } \\
\text { de eventos } \\
\text { científicos }(1) \\
\text { periódico } \\
\text { científico (1) }\end{array}$ & $\begin{array}{l}\text { Anais do Intercom Sul, Educom Sul e } \\
\text { Intercom Nacional (1); publicações } \\
\text { da Associação Brasileira de Criadores } \\
\text { Ovinos (ARCO) e da La Propaganda } \\
\text { Rural (1) }\end{array}$ & $2 /-$ & $2(3,03 \%)$ \\
\hline $\begin{array}{l}\text { Outro/não } \\
\text { tem objeto } \\
\text { midiático }\end{array}$ & $\begin{array}{l}\text { Políticas públicas } \\
(2) ; \text { projeto } \\
\text { cultural (1); } \\
\text { interação social } \\
\text { não mediada (1) }\end{array}$ & $\begin{array}{l}\text { Políticas - programa Mais Educação } \\
\text { em Santa Maria-RS (1); cartilha } \\
\text { Relações étnico-raciais e de gênero, } \\
\text { do Ministério da Educação (1) } \\
\text { Projeto - Vô Venâncio vai à escola } \\
\text { (1) } \\
\text { Interação - entrevista (1) }\end{array}$ & $3 / 1$ & $4(6,06 \%)$ \\
\hline
\end{tabular}

Fonte: elaborado pelos autores.

Para além dos dados elucidados na tabela, relativos a 64 teses e dissertações, ressalta-se que uma dissertação abordou concomitantemente dois objetos empíricos, rádio e televisão; a pesquisa não especifica o tipo de objeto midiático, nem o título/veículo do produto analisado. Ademais, uma tese não especifica seu objeto empírico.

\subsection{Análise dos dados coletados}

Decorrem da coleta de dados importantes considerações sobre os objetos empíricos selecionados para as investigações desenvolvidas na linha de pesquisa Mídias e Identidades Contemporâneas (POSCOM/UFSM) entre os anos de 2008 e 2017, cujas presenças podem ser observadas nas porcentagens do gráfico apresentado a seguir. 
Gráfico 1 - Porcentagem dos objetos empíricos

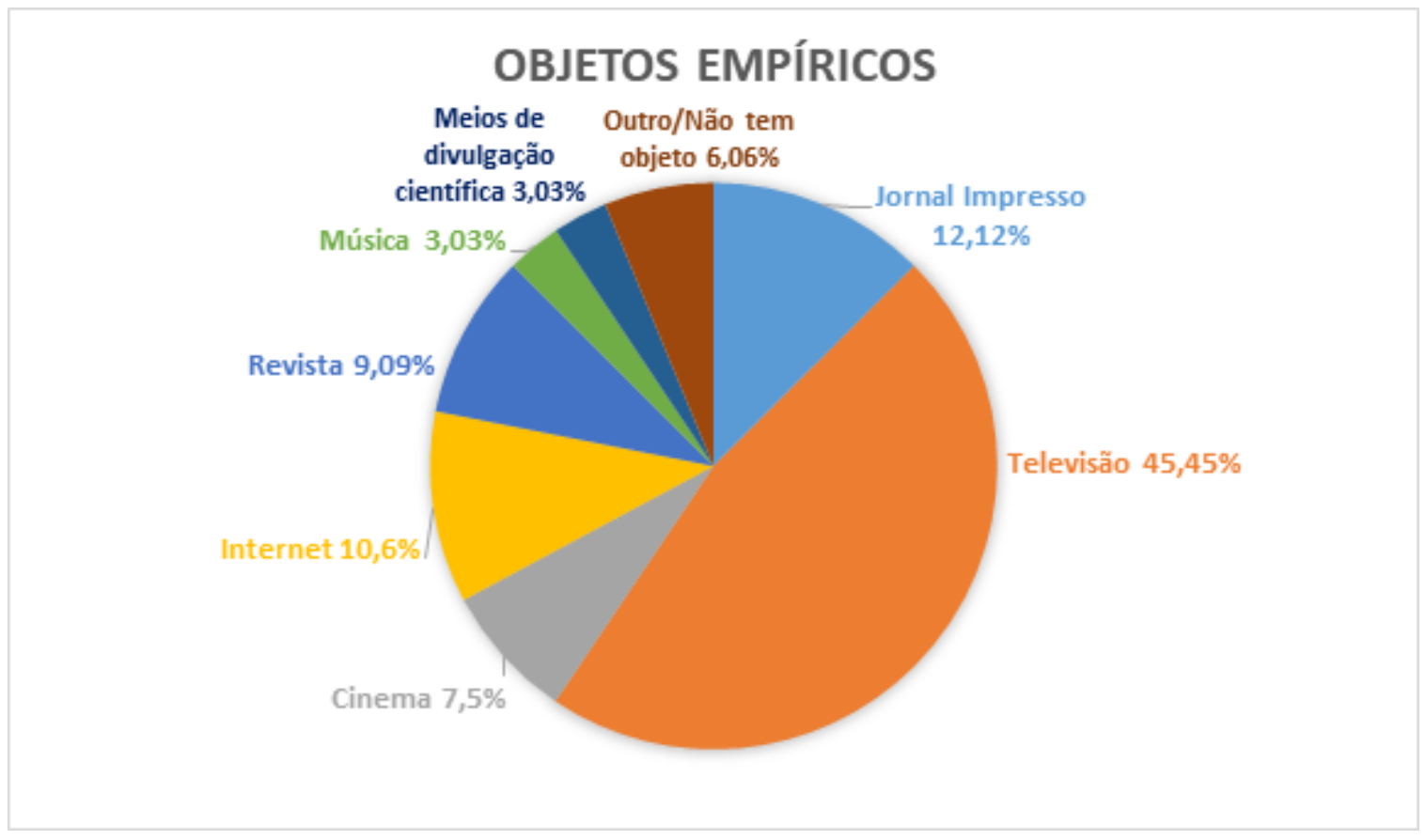

Fonte: elaborado pelos autores.

O gráfico ilustra a predominância de investigações que contemplam a televisão como objeto empírico, com o total de 30 pesquisas, o que representa 45,45\%. A emissora de televisão que mais teve atenção foi a Rede Globo de Televisão: 16 trabalhos dedicaram-se a investigar produtos da emissora; destes, cinco versaram sobre telenovelas através de estudos de recepção, principalmente a partir da perspectiva dos estudos culturais latino-americanos que tem como foco os processos de mediações. Tais pesquisas têm como perfil principal o objetivo de compreender os processos de mediação entre as necessidades "do sistema industrial e estratégias comerciais e as exigências que vêm da trama cultural e modos de ver" (MARTÍNBARBERO, 1995, p. 40).

Outra emissora que se destacou foi a RBS TV, filiada da Rede Globo no sul do Brasil, tendo cinco de suas produções como objeto de estudo nas pesquisas analisadas, ademais de uma dissertação que estudou a RBS TV Chapecó. Contrapondo a recorrência da televisão, se evidencia o fato de o rádio aparecer somente em um trabalho, numa análise que contempla, também, a televisão como objeto empírico.

Ainda em relação aos estudos sobre televisão, é interessante notar a diversidade de abordagens sobre o mesmo objeto empírico, o que nos permite refletir e ilustrar acerca da constituição do objeto de conhecimento. Duas dissertações abordaram a telenovela Passione, ambas defendidas no ano de 2011. Enquanto que Renata Córdova da Silva se dedica a um 
estudo de recepção com mães e filhas das classes populares para perceber como elas elaboram sua percepção de feminino a partir da telenovela, Laura Hastenpflug Wottrich analisa as relações entre as representações da velhice e suas apropriações por mulheres idosas das classes populares. Verifica-se, também, que os referenciais teóricos dessas pesquisas indicam pontos de aproximação e de diferença, ponderação que auxilia na compreensão de como a ancoragem teórica é basilar na formulação da problemática da pesquisa e, consequentemente, do objeto de conhecimento, como sentencia França (2016). Para exemplificar, ao passo que Stuart Hall e Néstor García-Canclini as unem ao escopo teórico culturalista, na pesquisa da Renata Córdova da Silva, Simone de Beauvoir está entre as principais referências para a reflexão sobre a identidade feminina, lente central à distinção analítica desta pesquisa em relação à outra.

As diferentes visadas para um mesmo objeto empírico podem ser elucidadas, outrossim, mediante análise das três dissertações que estudaram o jornal impresso Zero Hora. Na dissertação, defendida em 2009, Vilso Junior Chierentin Santias investigou as representações do Movimento dos Trabalhadores Rurais sem Terra no referido jornal através de um estudo de recepção e representação baseado nos preceitos teórico-metodológicos de Circuito da Cultura e Circuito das Notícias, oriundos dos Estudos Culturais Britânicos. Já a dissertação de Anaqueli Rubin, defendida em 2011, buscou identificar os valores-notícia dos acontecimentos climáticos no jornal Zero Hora; a autora analisou 41 edições do jornal e a cobertura de 90 acontecimentos climáticos, para desvelar como é representada a relação entre homem e clima. Os principais pressupostos teórico-metodológicos mobilizados foram os da Teoria da Representação de Stuart Hall, Patrick Charaudeau e Cristina Ponte. Por fim, a dissertação de Ananda Delevati, defendida em 2012, focou nas fontes especializadas consultadas no jornal Zero Hora para a cobertura de desastres que envolvem o clima, buscando os antagonismos e as compatibilidades entre o campo do jornalismo e o das fontes especializadas. Os métodos utilizados foram revisão bibliográfica, pesquisa documental e entrevistas semiabertas e semiestruturadas.

Pertinente destacar que em ambos os casos de repetição de objeto empírico - clarifica-se: a telenovela Passione, estudada em duas dissertações, e o jornal Zero Hora, objeto de três dissertações - trata-se de pesquisas orientadas pelas mesmas professoras, o que demonstra a diversidade de abordagens teórico-metodológicas desenvolvidas no seio dos grupos de pesquisa que compõem o POSCOM/UFSM.

O segundo objeto com maior presença é o jornal impresso, estando em 12,12\% do total de teses e dissertações. Trata-se de um produto midiático que pode ser considerado de análise tradicional, presente desde as primeiras investigações realizadas no campo da comunicação 
(MARQUES DE MELO, 2003). Percebemos uma variedade considerável de pesquisas que o utilizam como fonte de observação do diálogo com a própria sociedade, uma vez que as análises se debruçam sobre notícias, reportagens, opinião, anúncios publicitários, entre outros segmentos do jornal.

Outro dado interessante é o fato de um objeto de estudo da internet aparecer pela primeira vez em uma dissertação de mestrado no POSCOM/UFSM no ano de 2009, através do trabalho de Mônica Pieniz intitulado “A apropriação do global para fins locais: as representações da identidade gaúcha em comunidades virtuais do Orkut”. A partir deste ano, pesquisas ligadas às produções em mídias digitais crescem no programa; outros seis trabalhos foram produzidos, incluindo cinco dissertações e uma tese, sobretudo voltados às práticas comunicacionais nas então novas redes sociais.

Segundo Recuero (2014), tal fato dá-se pois foi principalmente o advento dos chamados sites de rede sociais, nesta mesma época, que gerou um novo impacto de percepção nos estudos comunicacionais. Isso porque, de acordo com a pesquisadora, esses sites não somente permitiram a representação individualizada dos atores, mas também a publicização de suas conexões. Neste sentido, “constituíram-se em suportes de redes, passando por apropriações sociais e emergentes, gerando novas práticas sociais com impacto na interconexão entre os indivíduos e no capital social construído" (RECUERO, 2014, p. 409). Desta forma, os objetos de pesquisa relativos às ambiências digitais contemporâneas, tais como comunidades virtuais no extinto Orkut, ambientes de comunicação em rede online em grupos de Facebook e a apropriação destas redes sociais online por parte de determinados grupos identitários passaram a estar presentes nas pesquisas do programa e até hoje configuram-se como uma das áreas mais importantes de estudo.

Mais um dado verificado é que as revistas impressas de circulação nacional semanal e mensal também estão entre os objetos de estudo mais investigados nos primeiros dez anos de pesquisa do POSCOM/UFSM, com seis trabalhos ao todo. Dentre eles, estão investigações dedicadas à reportagem de capa, anúncios publicitários, editoriais e estudos dedicados a notícias e reportagens jornalísticas, principalmente através da perspectiva de análise de discurso, uma das metodologias mais aplicadas no programa (KEGLER et al., 2020). No bojo dessa discussão recorda-se Meditsch e Schwaab (2014, p. 288) ao ressaltarem que "a singularidade do campo jornalístico solicita revisar constantemente as bases que permitiram o surgimento e o desenvolvimento do jornalismo, recolocando de forma sistêmica os textos clássicos em 
discussão", para, assim, dar conta das intensas transformações do mundo profissional através de diferentes objetos de interesse do campo.

Outro objeto de estudo presente tanto nas pesquisas de mestrado quanto de doutorado refere-se à área de produção audiovisual latino-americana, mais especificamente ao cinema, com cinco investigações ao todo. Entre os documentários estudados estão: Walachai, Berlim Brasil, Doble Chapa e Linha Imaginária. Foram abordadas também aspectos referentes a discussão de identidades contemporâneas em documentários queer, além de filmes brasileiros em acervos relacionados ao circuito exibidor em Nova Iorque, Estados Unidos. Estes estudos, em sua maioria, dedicam-se à análises e investigações teóricas, históricas e estéticas do cinema para compreender as identidades em contextos sociais reais.

Ainda se somam aos objetos até aqui analisados na produção do POSCOM/UFSM entre 2008 e 2017 a música e a produção sonora inseridas no contexto da indústria cultural contemporânea. Dois trabalhos dedicaram-se a este campo de estudo através de diferentes gêneros musicais, entre eles a cultura hip hop, a partir da realização de uma investigação teórica e empírica para compreender as interações entre moda e o rap, e uma pesquisa sobre a chamada tchê music e a música campeira, tema da primeira dissertação defendida no programa, que procurou compreender como se constitui a identidade no Rio Grande do Sul a partir do consumo destes dois movimentos de música regional.

À guisa de conclusão analítica, torna-se válido aludir duas dissertações que têm como objeto de estudo meios de divulgação científica relacionados à área de pesquisa em Comunicação. Uma delas analisa papers de anais de eventos; a outra, dois periódicos científicos.

É interessante notar, finalmente, que nem todas as pesquisas se debruçam à análise dos conteúdos midiáticos ou do consumo destes. Já dizia Braga (2011): interessam ao campo científico da Comunicação as ações sociais comunicacionais, enquanto objetos empíricos. Nos termos de França (2016), é o olhar do pesquisador que transforma ações em objetos comunicacionais, sejam elas mediadas por tecnologias midiáticas ou não. Dedicar atenção a estes aspectos é acenar para a necessidade de compreensão sobre a amplitude do campo de pesquisa, sua complexidade e transversalidade com outras áreas do conhecimento. Neste sentido, sublinham-se quatro pesquisas que se dedicaram à análise em torno de políticas públicas, projeto cultural e interação social não mediada, à margem da cena midiática hegemônica. 


\section{CONSIDERAÇÕES FINAIS}

Após a análise das investigações desenvolvidas na linha de pesquisa Mídias e Identidades Contemporâneas do POSCOM/UFSM referentes à primeira década de produção efetiva do programa (2008-2017), concluímos que a maioria dos trabalhos possui mais de um objeto empírico, algo que mais uma vez reflete e reforça a pluralidade e diversidade do campo comunicacional brasileiro, inserido em um contexto de pesquisas latino-americanas, assim exposto na introdução deste artigo.

Por um lado, constatamos que as pesquisas que contemplam a televisão como objeto empírico representam quase a metade do total de 66 teses e dissertações, estando em 30 trabalhos, o que, percentualmente, corresponde a 45,45\%. Por outro lado, o rádio não se apresenta como objeto empírico significativo no levantamento realizado, constando apenas em uma pesquisa que também analisou a televisão.

Uma unanimidade constatada é que todos os trabalhos possuem objetos de estudo inseridos direta ou indiretamente em diferentes processos comunicacionais, respeitando a coerência e fazendo jus ao rigor acadêmico requerido em um programa de pós-graduação na área de Comunicação. Grande parte deles trata desses processos, como já enfatizado, desde a perspectiva dos estudos das mediações socioculturais para compreensão das identidades contemporâneas, característica fundamental e ubíqua do programa ao longo destes dez primeiros anos.

Por fim, apesar de a área de concentração do POSCOM/UFSM atentar para os fenômenos midiáticos e todas as questões pertinentes a este campo de estudo - prestes à ganhar maturidade acadêmica -, a orientação analítica proposta nos permitiu observar que os objetos de estudo investigados demonstram que os trabalhos de dissertação e tese nos primeiros dez anos do programa já davam sinais de extrema atenção ao sabor dos tempos e norteavam os rumos que a pesquisa em comunicação iria agora tomar na terceira década do século XXI, prestes a começar. Tais pesquisas já se dedicavam, por exemplo, às ações sociais não convencionais à cena midiática e às ambiências digitais contemporâneas que agora nos parecem hegemônicas e onipresentes.

É possível dizer, assim, que há pesquisa em Comunicação além da mídia e há mídia além da pesquisa em Comunicação. Ou seja, os objetos midiáticos não definem e não são exclusivos ao campo científico da Comunicação, assim como podem ser - e são - estudados em outras áreas do conhecimento. 
Desse modo, buscamos mostrar no artigo um inventário dos objetos empíricos utilizados nas pesquisas desenvolvidas na primeira década do POSCOM/UFSM, levantamento que pode ser útil aos interessados em ingressar no programa e que buscam conhecer as pesquisas realizadas na linha de Mídias e Identidades Contemporâneas.

\section{REFERÊNCIAS}

BRAGA, José Luiz. Constituição do campo da comunicação. Verso e reverso, São Leopoldo, v. 25, n. 58, p. 62-77, 2011.

FRANÇA. Vera. O objeto de pesquisa em comunicação: uma abordagem relacional. In: MOURA, Claudia Peixoto. LOPES, Maria Immacolata Vassallo de. (Org.). Pesquisa em comunicação: metodologias e práticas acadêmicas. Porto Alegre: EDIPUCRS, 2016.

GIL, Antônio Carlos. Como elaborar projetos de pesquisa. 5 ed. São Paulo: Atlas, 2010.

KEGLER, Bruno; CURI, Guilherme; HARTMANN, Camila; DEWES, Helyna. A primeira década de produção científica nas pesquisas e Mídias e identidades contemporâneas do POSCOM/UFSM. Animus. Revista Interamericana de Comunicação Midiática, Santa Maria, v. 19, n. 41, 2020.

LOPES, Maria Immacolata Vassallo de. Pesquisa em Comunicação. 7 ed. São Paulo: Edições Loyola, 2003.

MALDONADO, Alberto Efendy. (Org.). Metodologias de pesquisa em comunicação: olhares, trilhas e processos. Porto Alegre: Sulina, 2006.

MARQUES DE MELO, José. História do pensamento comunicacional: cenários e personagens. São Paulo: Paulus, 2003.

MARTÍN-BARBERO, Jesús. América Latina e o anos recentes: o estudo de recepção em comunicação social. In: SOUSA, Mauro Wilton de. Sujeito, o lado oculto do receptor. São Paulo: ECA-USP/Brasiliense, 1995.

MARTINO, Luís Mauro Sá. Métodos de Pesquisa em Comunicação: projetos, ideias, práticas. Petrópolis: Vozes, 2018.

MEDITSCH, Eduardo e SCHWAAB, Reges. JORNALISMO. In: CITELLI, Adilson et al. Dicionário de Comunicação: escolas, teorias e autores. São Paulo: Contexto, 2014.

RECUERO, Raquel. Redes Sociais. In: CITELLI, Adilson et al. Dicionário de Comunicação: escolas, teorias e autores. São Paulo: Contexto, 2014. 
Guilherme Oliveira Curi Pós-doutorando e professor colaborador do Programa de Pós-Graduação em Comunicação da Universidade Federal de Santa Maria (POSCOM/UFSM)

Bruno Kegler

Docente da Universidade de Santa Cruz do Sul (UNISC) e pós-doutorando do Programa de Pós-Graduação em Comunicação da Universidade Federal de Santa Maria (POSCOM/UFSM)

Camila Hartmann

Doutoranda do Programa de Pós-Graduação em Comunicação da Universidade Federal de Santa Maria (POSCOM/UFSM)

Helyna Dewes Doutoranda do Programa de Pós-Graduação em Comunicação da Universidade Federal de Santa Maria (POSCOM/UFSM)

\section{@ $\odot \Theta \odot$}

Esta obra está licenciada com uma Licença

Creative Commons Atribuição-NãoComercial-CompartilhaIgual 4.0 Internacional 